\title{
BROCA GIGANTE DA CANA-DE-AÇÚCAR, TELCHIN LICUS LICUS (DRURY, 1773) NA REGIÃO CENTRO-SUL: PREOCUPAÇÃO PARA OS PRODUTORES
}

SILVA JUNIOR, Mauricio Pacheco da ${ }^{1}$

NICOLA, Murilo Vedovato ${ }^{1}$

ROSSI, Marta Maria ${ }^{2}$

Recebido em: 2008-10-06

Aprovado em: 2008-06-16

ISSUE DOI: $10.3738 / 1982.2278 .90$

RESUMO: A cultura da cana-de-açúcar expande suas fronteiras a cada ano, por todo o território nacional. Com isso, aumenta, a quantidade de biomassa que será aproveitada pelo homem, na produção de açúcar e álcool e, também, por outros organismos, que terão alimentos em abundância. O crescimento da colheita mecanizada com a conseqüente diminuição da queima da palha e a expansão do setor sucroalcooleiro estão provocando mudanças da entomofauna de determinadas áreas ou regiões de canavieiras. Uma das novas ameaças às plantações de canade-açúcar na região Centro-Sul, causando incerteza e inquietação aos produtores, é a broca gigante, Telchin licus licus (DRURY, 1773). Esse inseto sempre foi considerado praga da cultura da cana-de-açúcar nas regiões Norte e Nordeste do país, sendo, somente agora, motivo de preocupação para os canaviais da região Centro-Sul. Essa constatação serve para alertar os produtores de cana-de-açúcar sobre o risco de disseminação da praga e os prejuízos que podem ser gerados por essa espécie.

Palavras-chave: Danos. Controle de pragas. Métodos de controle.

\section{WORM GIANT FROM SUGAR CANE Telchin licus licus Drury, 1773) IN SOUTH- CENTRAL REGION : PREOCCUPATION TO THE FARMERS}

SUMMARY: The sugar cane plantation expands its borders each year, throughout the national territory. Thus, increases the amount of biomass that will to be exploited by man in sugar and alcohol produce and also by other organisms, which will have food in abundance. The growth of mechanized harvesting, with the consequent decrease in burning of straw and the expansion of the sucroalcooleiro sector are causing changes into entomofauna in certain areas or regions of sugar cane plantation. One of the new threats to the sugar cane plantations in southcentral region, causing uncertainty and concern to farmers, is the giant worm, Telchin licus licus (DRURY, 1773). This worm has always been considered pest in sugar cane plantation in the North and Northeast regions of the country, and, just nowadays, it is a matter of concern to the sugarcane from South Centre region. This observation is to alert the sugar cane farmers about the risk of spread of the pest and damage that can be generated by this specie.

Keywords: Damage. Pest control. Methods of control.

1 Pós-graduando em Agronomia, Gestão e Tecnologia Sucroalcooleira da Faculdade Dr. Francisco Maeda/ FEI. Rod. Jerônimo Nunes Macedo, km 01, caixa postal 111, CEP14500-000, Ituverava-SP.

Engenheiros Agrônomos pela Fundação Faculdades Luiz Meneghel - UENP, Bandeirantes/PR.

2 Professora Doutora da Faculdade "Dr. Francisco Maeda"/FAFRAM. Rod. Jerônimo Nunes Macedo, km 01, caixa postal 111, CEP14500-000, Ituverava-SP e do Centro Universitário Moura Lacerda (CUML) em Ribeirão Preto/SP. 


\section{INTRODUÇÃO}

O crescimento da colheita mecanizada com a conseqüente diminuição da queima da palha e a expansão do setor sucroalcooleiro, está provocando mudanças no conjunto de espécies da entomofauna de determinadas áreas ou regiões de canaviais. Uma das novas ameaças às plantações de cana-de-açúcar na região Centro-Sul, causando incerteza e inquietação aos produtores, é a broca-gigante, Telchin licus licus (DRURY, 1773), recentemente detectada no Estado de São Paulo.

Este inseto, sempre, foi considerado praga da cultura da cana-de-açúcar nas regiões Norte e Nordeste do país, sendo, somente agora, motivo de preocupação para os canaviais da região Centro-Sul. Essa constatação serve para alertar os produtores de cana-de-açúcar sobre o risco de disseminação da praga e dos prejuízos que podem ser gerados por essa espécie.

$\mathrm{O}$ assunto, atualmente, tem sido amplamente discutido em reuniões e eventos voltados para o setor sucroalcooleiro, porém ações concretas deverão ser adotadas para impedir o avanço deste inseto que se anuncia como o grande problema fitossanitário em áreas de plantio da canade-açúcar, nos próximos anos.

As lagartas da broca gigante impressionam por apresentarem tamanho avantajado, chegando a $80 \mathrm{~mm}$ de comprimento e $12 \mathrm{~mm}$ de largura do protórax e por apresentarem este período relativamente longo (até 10 meses), podendo causar os mesmos danos que a broca da cana-de-açúcar, porém em proporções bem maiores.

Esta revisão tem por objetivo, discutir os principais aspectos relacionados a esta praga, alertando produtores e especialistas para a busca de novos métodos para seu controle.

\section{REVISÃO DE LITERATURA}

A primeira citação de ocorrência da broca gigante danificando a cana-de-açúcar no Brasil foi de um autor anônimo em 1912, sem definir, porém, o local de ocorrência (MENDONÇA et al, 1996). Posteriormente, diversos autores relataram a ocorrência deste inseto danificando diferentes culturas, principalmente nos Estados do Norte e Nordeste do Brasil, sendo que sua presença foi observada pela primeira vez, na região Centro Sul, atacando canaviais em Uberlândia e Araguari, Estado de Minas Gerais, no ano de 1983.

Recentemente, em julho de 2007, sua presença foi novamente relatada na propriedade agrícola denominada Chácara Paineira, localizada no município de Limeira/SP, em canavial cultivado com a variedade SP86155 (ALMEIDA et al, 2008).

Esta migração repentina, os danos consideráveis que causa, além da dificuldade para obter um controle satisfatório dessa praga, são os principais motivos para a inquietação a incerteza por parte dos produtores de cana-de-açúcar.

Embora alguns pesquisadores acreditem que esta praga deverá ocorrer somente em 
áreas restritas (ANSELMI, 2008), sua ameaça assusta a todos, uma vez que, devido aos seus hábitos, seu controle ainda é difícil e, muitas vezes, sua infestação só é percebida após o corte da cultura.

A literatura relata uma vasta revisão feita por Mendonça et al. (1996) a respeito de sua taxonomia e bioecologia.

Os adultos da broca gigante têm cerca de $35 \mathrm{~mm}$ de comprimento e $90 \mathrm{~mm}$ de envergadura e são de coloração escura ou quase preta, com algumas manchas brancas na região apical e uma faixa transversal branca nas asas anteriores. As asas posteriores apresentam uma faixa curva e transversal de coloração branca e 7 manchas vermelhas na margem externa. No Nordeste do Brasil, os adultos surgem no período do verão, com vôo diurno e rápido; as fêmeas, após o acasalamento, efetuam a postura que varia de 50 a 100 ovos, em touceiras velhas, de preferência no meio de detritos e de caules cortados (GALLO et al, 2002).

Os ovos apresentam, inicialmente, uma coloração rosada e, posteriormente, adquirem a coloração verde-azeitona e alaranjada. Possuem $4 \mathrm{~mm}$ de comprimento, com cinco arestas longitudinais e apresentam um período de incubação variável de 7 a 14 dias. As lagartas são grandes, com até $80 \mathrm{~mm}$ de comprimento e $12 \mathrm{~mm}$ de largura do protórax, de coloração branca com algumas pintas pardas no pronoto, sendo que sua largura decresce da parte torácica para a anal. O período larval pode atingir até 10 meses, e as lagartas passam por cinco instares (BOTELHO et al, 2006). Assemelham-se às larvas de besouros da família Cerambycidae (ZUCCHI et al, 1993). A literatura não relata estudos da biologia e desenvolvimento desses insetos na região Centro-Sul do Brasil, provavelmente, devido às dificuldades de se criar, em laboratório, insetos com um ciclo de vida tão longo.

A pupa se transforma dentro de um casulo feito de fibras de cana-de-açúcar, mede cerca de $4 \mathrm{~cm}$ de comprimento (MENDONÇA et al, 1996) e dura de 30 a 45 dias, ocasião em que emergem os adultos que têm longevidade de 10 a 15 dias (BOTELHO et al, 2006).

Os sintomas são muito parecidos com os da broca da cana-de-açúcar Diatraea saccharalis, porém em proporções muito maiores. As lagartas perfuram internamente o colmo causando a morte da cana nova, perda em peso, "coração morto", falha na brotação (destruição dos toletes) e destruição completa do colmo em canas já desenvolvidas, além de criar condições para o aparecimento de podridões (MENDONÇA et al, 1996; GALLO et al., 2002).

$\mathrm{Na}$ cana recém brotada, principalmente nas soqueiras, as lagartas, em busca de alimento de melhor qualidade, saem da touceira e atacam os rebentos, destruindo seu poro vegetativo e apodrecendo sua gema apical. Com a mínima perturbação, as lagartas procuram proteger-se, enterrando-se profundamente, nos túneis abertos anteriormente nos rizomas ou entre as raízes, o que permite que elas se preservem na cultura. Logo após o corte da cana, a lagarta tem o hábito de vedar, com restos de fibras, o orifício deixado aberto pela galeria interna onde vivia, visando a proteger-se, passando a viver escondida durante o dia, na parte mais profunda e fresca da touceira, alimentando-se do rizoma, de restolhos e de raízes, debilitando e reduzindo o poder germinativo da touceira (PINTO et al, 2006). 
Devido à ausência de informações sobre a bioecologia da praga, e principalmente, um método de amostragem adequado, seu nível de controle ainda não foi determinado.

Para Almeida et al (2008), o monitoramento desta praga deve ser realizado nas áreas suspeitas, avaliando-se 18 touceiras de cana/ha, conforme o esquema de caminhamento proposto pelo Centro de Tecnologia Canavieira. Recomenda-se priorizar áreas próximas de viveiros de plantas ornamentais e áreas de reforma, com atenção aos tipos de danos ocorridos nas touceiras e também às formas biológicas encontradas, devendo os dados serem registrados em fichas de campo.

O levantamento de ocorrência da broca gigante deve ser realizado por volta de 3 meses após a brotação da soqueira, dirigindo a procura da praga em canas que apresentam o sintoma de "coração-morto", sendo os dados informados na ficha de campo.

Segundo Pinto et al. (2006), os métodos de controle que já foram tentados são os métodos: químico, mecânico, mecânico-químico, biológico, mecânico-biológico e de resistência de plantas, porém sem grandes êxitos. O método de controle utilizado por grande número de produtores, na região Nordeste consiste na retirada dos rizomas infestados e catação das formas biológicas presentes, efetuando-se o pagamento aos trabalhadores com base no número de insetos coletados. Se utilizado em larga escala, pode contribuir para a redução da população da praga; porém, se realizado por número reduzido de produtores ou em pequenas áreas, terá sua eficiência comprometida. Os custos operacionais das coletas das formas biológicas, com a finalidade de reduzir as populações da broca gigante, são elevados (ALMEIDA et al, 2008). Apenas a "catação manual de lagartas e de pupas" e a captura de adultos com rede entomológica possibilitam bons resultados, porém com baixa rentabilidade, não devendo ser predominante na região Centro-Sul.

As medidas legislativas de controle deveriam ser as primeiras a serem adotadas e de forma rigorosa, uma vez que existem duas hipóteses para este início de infestação: a primeira é que a transmissão teria ocorrido através de plantas ornamentais, trazidas de regiões onde esta praga apresenta ocorrência natural, a partir de viveiros onde são cultivadas e comercializadas estas plantas hospedeiras, entre elas as musáceas e orquidáceas; a outra, mais provável, é que esta introdução se fez por meio de mudas de cana. Assim sendo, a inspeção fitossanitária nas canas a serem transportadas e os tratamentos químico e térmico, que já foram preconizados por Araújo Filho e Guagliumi (1969) apud Mendonça et al, (1996) deveriam ser colocados em prática, tornando-se indispensáveis para evitar a disseminação da praga que iniciou seu ataque em 13 hectares em 2007 e, em 2008, já havia aumentado essa área para 600 ha (ANSELMI, 2008).

O estudo do fungo B. bassiana para o controle de T. licus. licus remonta à década de 1980. Os testes feitos em laboratório sempre demonstraram possibilidades de sua utilização no controle biológico da broca gigante (VILAS BOAS et al, 1983), porém os testes, em condições de campo, sempre, foram insatisfatórios (MARQUES et al, 1984, 1986). Marques et al, (2001) citados por Figueiredo et al, (2002), comprovaram que alguns, isolados de M. anisopliae, 
apresentaram patogenicidade para a broca gigante, sendo de $70 \%$ a maior porcentagem de mortalidade obtida. Figueiredo et al, (2002) testaram, em laboratório, diversos isolados de fungos entomopatogênicos, Beauveria bassiana e Metarhizium anisopliae provenientes de diversos hospedeiros e localidades, contra a broca gigante da cana-de-açúcar. Os isolados de B. bassiana provocaram mortalidade, variando entre 53,3 e 83,3\%, enquanto, que para M. anisopliae, o percentual de lagartas mortas variou entre 43,3 e $80 \%$, demonstrando seu potencial para o controle desse inseto.

É importante mencionar que não são conhecidos, no Brasil, inimigos naturais eficientes na redução das populações de . licus licus, em qualquer das fases do seu desenvolvimento biológico. O controle natural dessa praga restringe-se à atividade de algumas aves que se alimentam da broca gigante nas áreas de cana-de-açúcar recém colhidas (ALMEIDA et al, 2008).

Para Botelho et al, (2006), o controle químico do inseto não tem se mostrado eficiente nas dosagens recomendadas pelos fabricantes. Nos últimos anos, alguns inseticidas químicos e/ou biológicos, eficientes em testes de laboratório, não apresentaram desempenho satisfatório no campo, por causa do hábito dos insetos que se protegem na base da touceira e em seguida escondem-se na parte posterior do colmo, realizando o fechamento do orifício o que impede a ação de qualquer produto. Este processo de tamponamento demora, apenas, de 10 a 15 minutos e, por isso, é importante que se desenvolvam metodologias adequadas para que os produtos químicos ou biológicos sejam colocados dentro da touceira, antes que o inseto se proteja.

As últimas novidades da pesquisa apontam para a possibilidade do desenvolvimento de um método eficiente para o controle dessa praga, ou seja, contornar o problema do tamponamento da praga, usando, por exemplo, o fungo $B$. bassiana imediatamente após a operação de corte da cana-de-açúcar, por meio de um pulverizador adaptado à colhedora. $\mathrm{O}$ objetivo é contaminar imediatamente a lagarta, antes que ela se esconda na touceira e se proteja, tornando-se inatingível por quaisquer métodos de controle. Anselmi (2007) afirmou que a aplicação do bioinseticida "driblou" as dificuldades de controles decorrentes do comportamento da broca gigante.

\section{CONSIDERAÇÕES FINAIS}

O estudo da broca gigante da cana-de-açúcar na região Centro-Sul do Brasil é ainda incipiente, e o perigo que esta praga oferece aos canaviais da maior região produtora de canade-açúcar do país é muito grande. Por esse motivo, é preciso que esforços sejam concentrados, visando a não somente impedir o avanço dessa praga, mas também buscar métodos de controle eficientes para combatê-la. 


\section{REFERÊNCIAS}

ALMEIDA, L. C; STINGEL, E; ARRIGONI, E. de B. Monitoramento e controle da broca gigante da cana-de-açúcar, Telchin licus. Centro de Tecnologia Canavieira, mar. 2008.

ANSELMI, R. Migração da broca gigante causa inquietação. Jornal da Cana, Tecnologia Agrícola, abr. 2008, p. 87-88.

ANSELMI, R. Fungo controla a broca gigante. Jornal da Cana, Tecnologia Agrícola, nov. 2007, p. 44-46.

BOTELHO, P. S; GARCIA, J. F; MACEDO, L. P. M. Outras lagartas que atacam a cana-deaçúcar. In: PINTO, A. de S. (org.) Controle de pragas da cana de açúcar, Biocontrol, Sertãozinho, 2006. p. 25-28. (Boletim Técnico Biocontrol, 1)

FIGUEIREDO, M.de F. de et al. Seleção de isolados de Beauveria bassiana (Bals.) Vuill e Metahizium anisopliae (Metsch) Sorok. contra a broca gigante da cana-de-açúcar Castnia licus (Drury) (Lepidoptera : Castniidae). Neotropical Entomology, v.31,n.3, p. 397-403, 2002.

GALLO, D. et al. Entomologia agrícola. Piracicaba: FEALQ, 2002. 920p.

MARQUES, E. J. et al. Efeito do fungo Beauveria bassiana (Bals.) Vuill e alguns inseticidas no controle de Castnia licus D., broca gigante da cana-de-açúcar. Bras. Açucareiro, v.102, p.36-39. 1984

MARQUES, E. J. et al. The potenciality of the Beauveria bassiana at the control of Castnia licus, the Giant Borer of Sugarcane. STAB, - Sugar, Alcohol by-prod. v.4, p.79-8,. 1986.

MENDONÇA, A. F; VIVEIROS, A. J. A. SAMPAIO FILHO, F. A broca gigante da cana-deaçúcar, Castnia licus Drury, 1770 (Lep.:Castniidae). In: MENDONÇA, A.F. (ed.). Pragas da cana-de-açúcar : Maceió: Insetos \& Cia., p. 133-167, 1996.

PINTO, A. de S; GARCIA, J. F; OLIVEIRA, H. N. de. Manejo das principais pragas da canade-açúcar. In: SEGATO, S. V et al. (org). Atualização em produção de cana-de-açúcar. Piracicaba, CP2, p. 257-280, 2006.

VILAS BOAS, A. M.; MARQUES, E. J; RIBEIRO, S. M. A. Patogenicidade do fungo Beauveria bassiana (Bals.) Vuill, sobre larvas de Castnia licus Drury (Lepidoptera, Castniidae), broca gigante da cana-de-açúcar. An. Soc. Entomol. Brasil, v.12, p.295-298. 1983.

ZUCCHI, R. A, SILVEIRA NETO, S, NAKANO, O. Guia de identificação de pragas agrícolas. Piracicaba: FEALQ, 139p, 1993. 